\title{
Article \\ Thin Film Gas Sensors Based on Planetary Ball-Milled Zinc Oxide Nanoinks: Effect of Milling Parameters on Sensing Performance
}

\author{
Raju Sapkota, Pengjun Duan, Tanay Kumar, Anusha Venkataraman $\mathbb{D}$ and Chris Papadopoulos * \\ Department of Electrical and Computer Engineering, University of Victoria, P.O. Box 1700 STN CSC, \\ Victoria, BC V8W 2Y2, Canada; rsapkota@uvic.ca (R.S.); pengjunduan@uvic.ca (P.D.); \\ tanaykumar@uvic.ca (T.K.); anushav@uvic.ca (A.V.) \\ * Correspondence: papadop@uvic.ca
}

Citation: Sapkota, R.; Duan, P.; Kumar, T.; Venkataraman, A.; Papadopoulos, C. Thin Film Gas Sensors Based on Planetary Ball-Milled Zinc Oxide Nanoinks: Effect of Milling Parameters on Sensing Performance. Appl. Sci. 2021, 11,9676. https://doi.org/10.3390/ app11209676

Academic Editor: Richard Yongqing Fu

Received: 3 September 2021

Accepted: 13 October 2021

Published: 17 October 2021

Publisher's Note: MDPI stays neutral with regard to jurisdictional claims in published maps and institutional affiliations.

Copyright: (c) 2021 by the authors. Licensee MDPI, Basel, Switzerland. This article is an open access article distributed under the terms and conditions of the Creative Commons Attribution (CC BY) license (https:/ / creativecommons.org/licenses/by/ $4.0 /)$.

\begin{abstract}
Planetary ball-milled zinc oxide $(\mathrm{ZnO})$ nanoparticle suspensions (nanoinks) were used to produce thin film chemiresistive gas sensors that operate at room temperature. By varying milling or grinding parameters (speed, time, and solvent) different thin film gas sensors with tunable particle sizes and porosity were fabricated and tested with dry air/oxygen against hydrogen, argon, and methane target species, in addition to relative humidity, under ambient light conditions. Grinding speeds of up to $1000 \mathrm{rpm}$ produced particle sizes and RMS thin film roughness below $100 \mathrm{~nm}$, as measured by atomic force and scanning electron microscopy. Raman spectroscopy, photoluminescence, and X-ray analysis confirmed the purity and structure of the resulting $\mathrm{ZnO}$ nanoparticles. Gas sensor response at room temperature was found to peak for nanoinks milled at $400 \mathrm{rpm}$ and for $30 \mathrm{~min}$ in ethylene glycol and deionized water, which could be correlated to an increased film porosity and enhanced variation in electron concentration resulting from adsorption/desorption of oxygen ions on the surfaces of $\mathrm{ZnO}$ nanoparticles. Sensor response and dynamic behavior was found to improve as the temperature was increased, peaking between 100 and $150{ }^{\circ} \mathrm{C}$. This work demonstrates the use of low-cost PBM nanoinks as the active materials for solution-processed thin film gas/humidity sensors for use in environmental, medical, food packaging, laboratory, and industrial applications.
\end{abstract}

Keywords: $\mathrm{ZnO}$; nanoparticles; planetary ball milling; gas sensor; thin films; nanoink

\section{Introduction}

Thin films and nanostructured coatings find broad application due to their unique properties, which is a result of both size and interface effects [1-8]. In particular, thin film gas sensing devices based on nanostructures are relevant for monitoring environmental gas concentration, controlling chemical processes, and agricultural and medical applications [9-12]. For efficient gas sensing, the film properties and structure play a vital role in sensor operation depending on particle size, porosity, and the diffusion time of the gas species [13]. Nanoparticles have a large relative surface area, thereby accelerating exchange with the surrounding atmosphere and leading to a larger detection signal relative to larger or bulk particles. A high porosity nanoparticle sensing film also facilitates the rapid diffusion of the gas species and improves sensing performance. Similarly, gas homogenization time for nanoparticles can be several orders of magnitude smaller than for micron-sized particles.

Semiconducting metal oxide nanostructures have shown exceptional chemical, optical, mechanical, and electrical properties for sensing [14-16]. Metal oxides show a large change in their electrical conductivity in the presence of various gas environments [15,17], and thus, by monitoring the variation of current (or resistance) through these films, they can function as sensitive gas detectors. Lowering the operating temperature needed for metal oxide gas sensors is an important goal, and room temperature operation, in particular, has attracted wide interest due to low-power consumption, portability, and cost-effectiveness [18]. 
Approaches such as noble metal functionalization or creation of oxygen vacancies have been proposed to reduce sensor working temperatures [19-22]. Various types of metal oxide films have been used for gas sensing applications, [11,16,23] including $\mathrm{TiO}_{2}$ [24], $\mathrm{SnO}_{2}$ [25], and $\mathrm{ZnO}$ [26-28]. Among these, $\mathrm{ZnO}$, a wide band gap ( 3.34-3.37 eV) [29] semiconductor, is widely used for applications such as varistors [30], memristors [31], solar cells [32], piezoelectric devices [33], and light emitting diodes [34]. Low resistivity, nontoxicity, large exciton binding energy, different nanostructured geometries, along with high surface-to-volume ratios make $\mathrm{ZnO}$ nanoparticles an excellent choice for optoelectronic and gas/vapor sensing applications [35,36]. ZnO is considered a "chemoresistive" sensing material, wherein the presence/absence of adsorbed oxygen species on its surface alters the amount of free carriers available to participate in charge transport [11,26], which can be used to sense, e.g., oxygen [27], hydrogen [20], ethanol [37], $\mathrm{NO}_{x}$ [38], acetone [39], $\mathrm{NH}_{3}$ [40], and $\mathrm{CO}$ [41].

In general, $\mathrm{ZnO}$ films can be prepared via various fabrication techniques, including chemical vapor deposition [42,43], atomic layer deposition [19,44], sputtering [38], spray pyrolysis [45], pulsed laser deposition [46], sol-gel [47], and ball milling [48-51]. In addition, various low-cost solution-based deposition techniques such as drop casting [47], spin coating [41], doctor blading [37], screen printing [52], and ink jet printing [53] have been adopted to produce $\mathrm{ZnO}$ thin films on different substrates. For example, doctor blading is often used due to its simplicity, cost-effectiveness, uniform and quick deposition, low energy, and minimal requirements for the suspension/ink [54].

Planetary ball milling (PBM) is known for its ability to reliably produce large amounts of nanoscale particles in appropriate solvents by grinding high-purity bulk powders [51,55-60] without requiring complex physical or chemical processing. Planetary mills are very energy efficient by utilizing the high-impact forces during rotary motion of a grinding jar containing the sample, grinding beads and a liquid medium, arranged eccentrically on a so-called sun wheel, which facilitates the rapid production of nanostructured thin films in an inexpensive manner. PBM has been used to produce nanoscale suspensions, or nanoinks, of $\mathrm{ZnO}$ for various applications, including antibacterial materials [51], varistors [49], catalysts [61], antifouling [62] and anode materials [63], luminescence [64], composites and alloys [65-67], gas sensors [68-71], UV sensors, and photodetectors [72-74]. The PBM process depends on various configurable parameters such as speed of revolution, milling time, and the ratio of beads to feed material. The grinding parameters and solvent used influence the properties and size distribution of the resulting nanoparticle inks and thin films [60], which can be optimized for different applications, including gas sensing.

In this paper, we combine PBM and doctor blading to produce $\mathrm{ZnO}$ nanoparticle thin film gas sensors that operate at room temperature via changes in film resistance upon exposure to different gas species. By varying grinding parameters and examining the effect on nanoparticle structure and electrical characteristics of the resultant films, we are able to tune the response signal magnitude and response/recovery times of the $\mathrm{ZnO}$ gas sensor devices. Tests conducted in dry/humid air and different target gas environments allowed us to study the $\mathrm{ZnO}$ film fabrication conditions required for optimal gas sensing and validate the feasibility of using PBM nanoinks as the active material for thin film gas sensors.

\section{Materials and Methods}

\subsection{Materials}

Zinc oxide powder (ZnO; Anachemia), ethylene glycol (EG; 99\% purity, BDH), deionized water (DI water), high-purity gases, and extra dry air (Praxair) were used as received. Glass slides were used as flat substrates for thin film coatings. Stainless steel single edge razor blades (GEM) were used for doctor blading. Conductive silver paint (Ted Pella) and copper tape (3M) were used to make electrical contacts to $\mathrm{ZnO}$ films. 


\subsection{Preparation of Nanostructured Thin Films and Sensor Fabrication}

PBM was performed using a Fritsch Pulverisette 7 planetary micro mill (premium line) (silicon nitride grinding jars, $80 \mathrm{~mL}$ capacity; zirconia grinding beads, $2 \mathrm{~mm}$ in diameter). In a typical experiment, $\mathrm{ZnO}$ powder $(\sim 7 \mathrm{~g})$ was ground in approximately $10 \mathrm{~mL}$ of either EG or DI water solvent (a.k.a. colloidal grinding) with approximately $100 \mathrm{~g}$ of beads. The grinding speed and time were varied between 200 and $1000 \mathrm{rpm}$ and $10 \mathrm{~min}$ and $60 \mathrm{~min}$ (in cycles of 5 min grinding, 5 min resting), respectively. After the completion of each grinding trial, a syringe and stainless-steel mesh were used to extract and separate the resulting PBM nanoink suspension from the grinding beads. Several films of each of the ground $\mathrm{ZnO}$ trials were prepared for characterization via doctor blading on substrates as follows: A few $\mu \mathrm{L}$ of $\mathrm{ZnO}$ nanoink was used to coat the surface by sweeping the blade across the substrate (masked with a single layer of Scotch tape) along with the suspension (blade angle 20-30 ). The film thickness for all prepared sensors was approximately $60 \mu \mathrm{m}$ (based on nominal scotch tape thickness). The coatings were dried at $\sim 100{ }^{\circ} \mathrm{C}$ on a hotplate for approximately $5 \mathrm{~min}$.

For thin film surface imaging, a Nanonics MultiView 1000 atomic force microscope (AFM) with Olympus BXFM optical microscope was employed. Additionally, Raman scattering measurements of thin film samples were performed using a Renishaw inVia Raman microscope. Raman spectra were collected using $632.8 \mathrm{~nm}$ HeNe laser line under ambient conditions. Photoluminescence (PL) spectra were acquired using an Olympus FV1000 confocal laser scanning microscope with solid state laser line of wavelength $405 \mathrm{~nm}$. Scanning electron microscopy (SEM) and energy dispersive X-ray analysis (EDX) were performed using a Hitachi S-2600. The thin film porosity and particle size analysis was performed using ImageJ (version 1.46r) [75].

To create the gas sensor devices, two electrical contacts to the resulting films were made using silver paint and copper tape (see Figure 1a), followed by drying in a mechanical oven for $10-15 \mathrm{~min}$ at $75^{\circ} \mathrm{C}$.

(a)
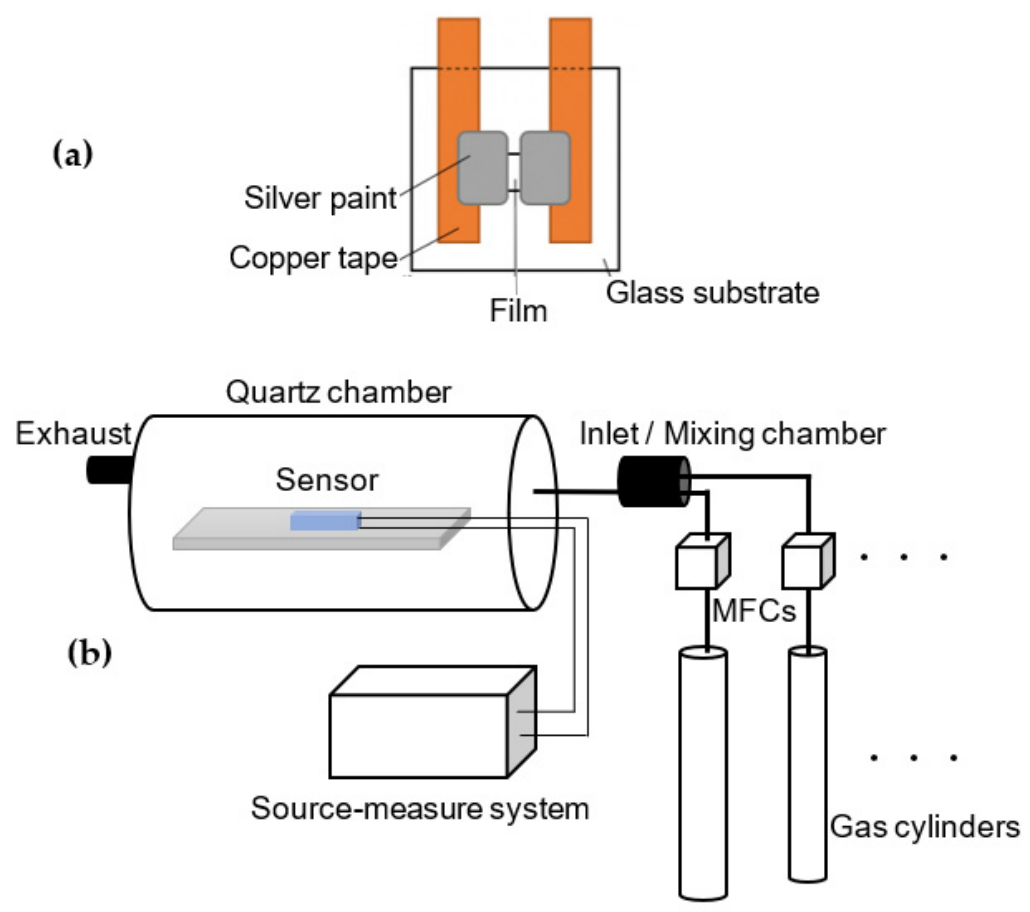

Figure 1. (a) Schematic diagram of thin film gas sensor devices: copper tape on glass substrates containing doctor bladed $\mathrm{ZnO}$ film served as the electrode contacts and silver paint were used for connecting sensor film to electrodes. (b) Illustration of the gas sensing apparatus used. The sensor was placed inside a quartz test chamber connected to gas cylinders (carrier and/or target gas) through MFCs. $\mathrm{Cu}$ wires were connected to the sample via a hermetic feedthrough for electrical measurements. The electrical response of the sensor was monitored using a precision source-measure system. 


\subsection{Sensor Characterization}

The gas sensing studies were conducted using the setup shown in Figure $1 \mathrm{~b}$, under ambient pressure and temperature (approximately $22^{\circ} \mathrm{C}$, unless indicated otherwise), which consisted of a 3-inch diameter quartz tube chamber connected to a precision electrical source-measure system (Keithley 4200-SCS) and compressed gas source(s) (target/carrier species) through mass flow controllers (MFCs). Two-terminal current-voltage (I-V) characteristics and current response versus time for the $\mathrm{ZnO}$ film sensors were measured in different gas environments. Before injecting target gases inside the chamber, a baseline sensor behavior in dry air carrier gas was determined. Relative humidity (RH) inside the test chamber was measured using a Digi-Sense 20250-11 pre-calibrated thermo-hygrometer. All experiments were performed under ambient room light.

\section{Results and Discussion}

\subsection{Film Morphology and Material Characterization}

An optical microscope image of a typical $\mathrm{ZnO}$ thin film coating formed using PBM nanoink and doctor blading is shown in the inset of Figure 2a. The coatings displayed good uniformity, stability, and adhesion under ambient conditions and up to $200{ }^{\circ} \mathrm{C}$. The SEM image in Figure 2a shows that the milled $\mathrm{ZnO}$ films consist of fine nanostructured particles with distributed pores. The $\mathrm{ZnO}$ film surface topography was further characterized using AFM (Figure 2b). As expected, particles were ground into finer sizes as grinding speed was increased, and we observed a reduction in root mean square (RMS) film roughness, as measured with AFM (Figure 2c), which drops below $80 \mathrm{~nm}$ for grinding at $1000 \mathrm{rpm}$ for $10 \mathrm{~min}$. Higher grinding speed also concurrently reduced particle size below $100 \mathrm{~nm}$ (Figure 2d). A similar decreasing trend in particle size/film roughness was observed as grinding time was increased (at constant rpm) (see Figure 2e) [60].

The photoluminescence spectrum of a typical film is shown in Figure $2 \mathrm{f}$. The milled $\mathrm{ZnO}$ thin films showed five different peaks of various intensity levels at different wavelength ranges, which can be correlated with the electronic and structural properties of the milled particles. Consistent with previous studies, the $465 \mathrm{~nm}$ peak (blue emission band) is attributed to deep level emission originating from oxygen vacancies or interstitial zinc ions of $\mathrm{ZnO}$ [76]. The green emission $(525 \mathrm{~nm})$ is due to singly ionized oxygen vacancy or oxygen antisite defect $\mathrm{O}_{Z n}$ [55]. Similarly, the peak at $577 \mathrm{~nm}$ is most likely due to disorder at the surface of nanoparticles after milling [55]. Lastly, the other peaks near $590 \mathrm{~nm}$ and $655 \mathrm{~nm}$ emission are usually attributed to oxygen vacancies $[77,78]$.

Raman spectra for both PBM nanoink thin films and bulk starting powder are shown in Figure $2 \mathrm{~g}$ and $\mathrm{h} . \mathrm{ZnO}$ most often has a wurtzite structure, and there are two $\mathrm{A}_{1}$, two $\mathrm{E}_{1}$, two $E_{2}$, and two $B_{1}$ modes in the Raman spectra of its crystal structure [79].

The most common Raman intensive $\mathrm{E}_{2}$ (low) mode at $\sim 99 \mathrm{~cm}^{-1}$ is just beyond the range of our detection; however, the other Raman mode, $\mathrm{E}_{2}$ (high), at $\sim 437 \mathrm{~cm}^{-1}$ is visible, which is assigned to oxygen vibrational modes [80]. $\mathrm{E}_{2}$ (high) mode is most prominent in the starting material; after milling, the intensity of the peak decreases and becomes broadened. Lowered intensity and peak broadening of the $437 \mathrm{~cm}^{-1}$ peak indicate a change in band structure and crystallinity of nanostructures after milling. The Raman spectra of both ground and bulk powder display three different peaks at about 206, 329, 379, and $412 \mathrm{~cm}^{-1}$, where these peaks are attributed to $2 \mathrm{TA}: 2 \mathrm{E}_{2}, \mathrm{E}_{2}$ (high)- $\mathrm{E}_{2}$ (low), $\mathrm{A}_{1}(\mathrm{TO})$, and $\mathrm{E}_{1}(\mathrm{TO})$ symmetry, respectively [80]. However, broader Raman peaks and lower intensity are attributed to size effects, lattice strain, and lower crystallinity $[55,81]$. The decrease in crystallinity is attributed to defects produced during ball milling. For the milled nanoparticles, we observed a broad peak around $580 \mathrm{~cm}^{-1}$ that became more prominent for longer grinding time or higher speeds. It is predicated that peaks with high intensity from 560 to $580 \mathrm{~cm}^{-1}$ indicate the presence of defects related to oxygen vacancy $\left(V_{0}\right)$ and/or zinc interstitial $\left(\mathrm{Zn}_{\mathrm{i}}\right)$ [80,82], which could be advantageous for gas sensing [19]. The milling media (grinding beads, solvents) can also affect the particles, but this is 
likely only significant for longer grinding times and/or higher speeds (see red curve in Figure $2 \mathrm{~h}$ - the peak at $189 \mathrm{~cm}^{-1}$ is assumed to be related to the zirconia grinding beads [83]).

The EDX results for our $\mathrm{ZnO}$ gas sensor films (Figure 2i) confirmed the presence $\mathrm{Zn}$ and $\mathrm{O}$ elements, with average atomic percentages of 48.05 and 51.95, respectively. The oxygen content percentage in the milled powder is likely affected by milling time and medium (e.g., solvents) $[55,84,85]$. In general, ball milling can also cause contamination from the grinding jar and beads [55,85]; however, our EDX results did not indicate the presence of appreciable elemental impurities for the PBM nanoinks studied.

(a)

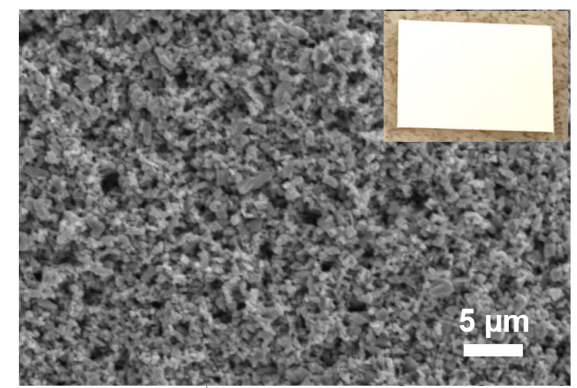

(c)

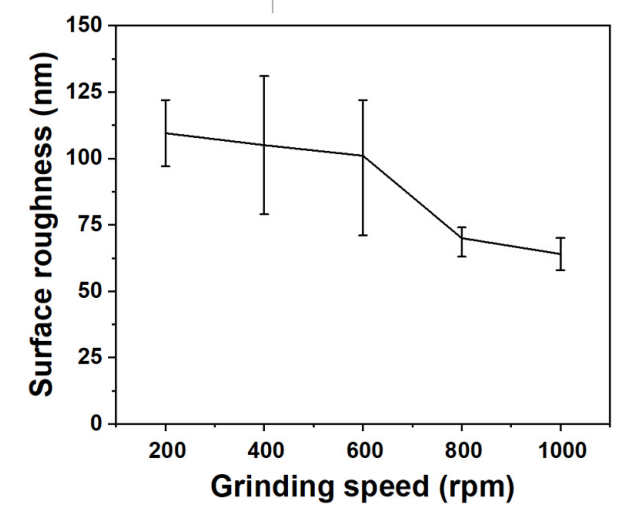

(e)

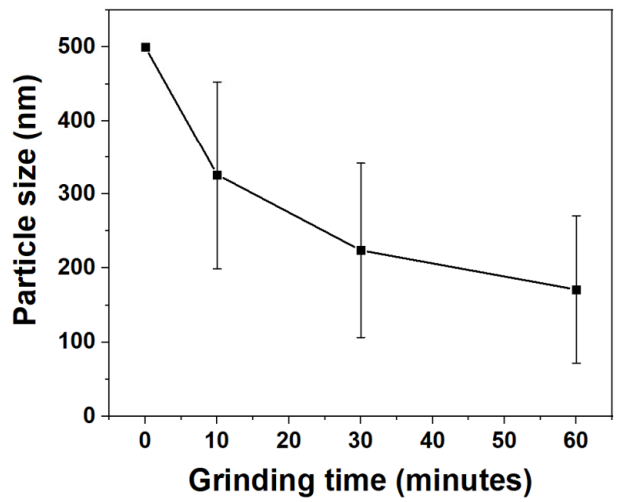

(b)

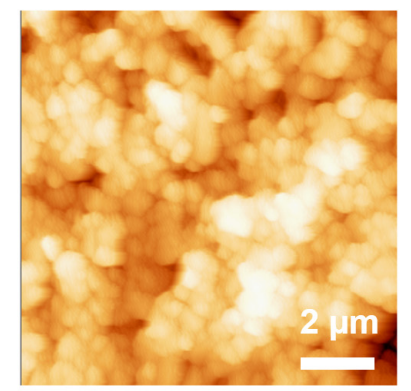

(d)

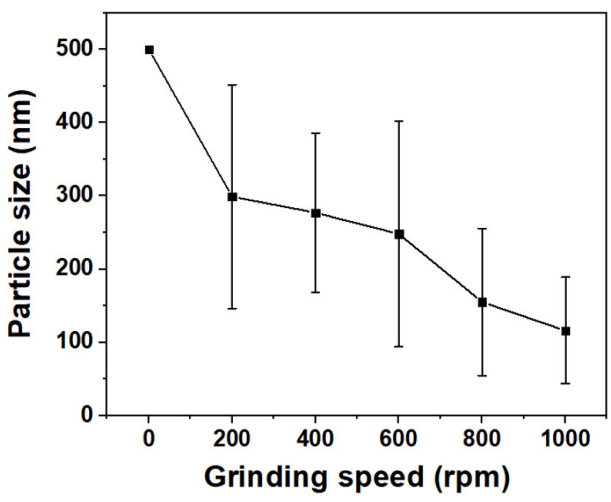

(f)

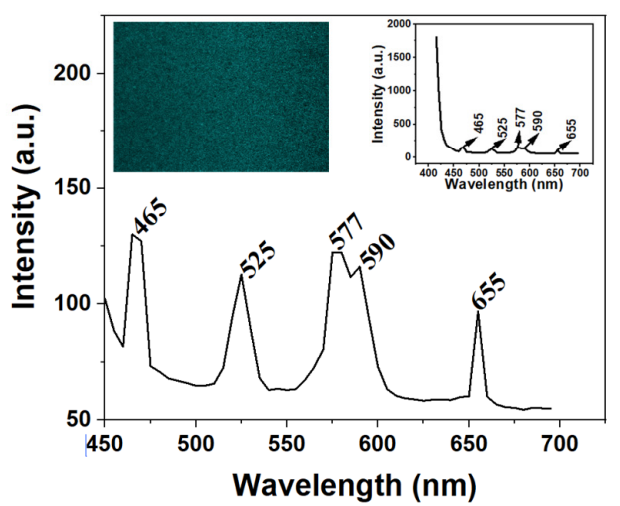

Figure 2. Cont. 

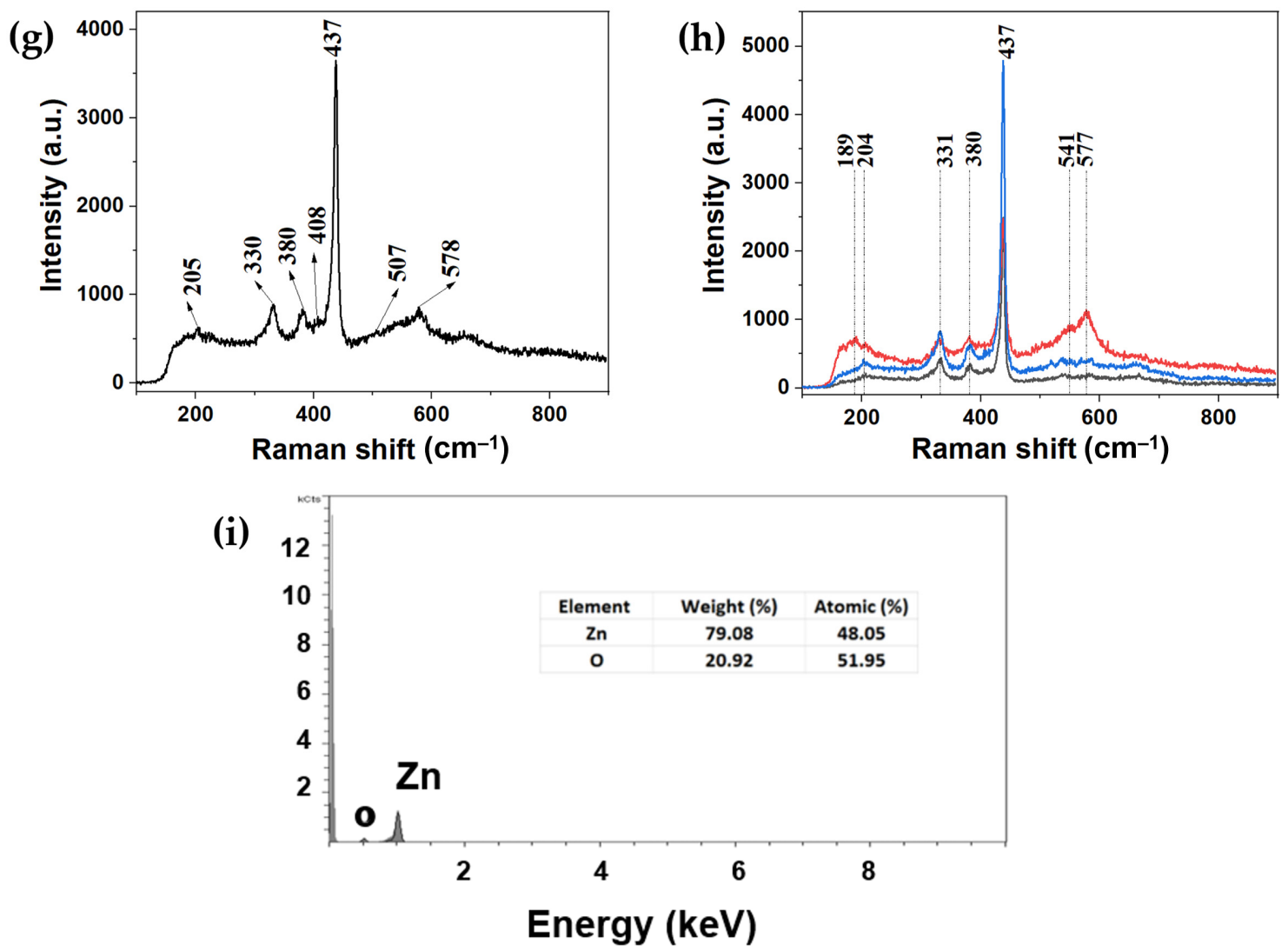

Figure 2. (a) SEM image of milled ZnO nanoparticles ground with DI water at $200 \mathrm{rpm}$ for $30 \mathrm{~min}$. The inset is an optical microscope image of doctor-bladed $\mathrm{ZnO}$ thin film on glass substrate. (b) AFM images of ZnO film prepared using PBM nanoink with DI water ground at $200 \mathrm{rpm}$ for $10 \mathrm{~min}$. (c) Plot of RMS roughness from AFM of ZnO thin films using PBM nanoink ground in EG for $10 \mathrm{~min}$ at different speeds. Average particle size of ZnO particles obtained from AFM and SEM data of thin films using PBM nanoink ground in (d) EG for 10 min at different speeds and (e) DI water at $200 \mathrm{rpm}$ for different grinding time (data at $0 \mathrm{rpm} / \mathrm{min}$ denote nominal starting bulk powder particle size). (f) Photoluminescence spectra for approximately 450-700 $\mathrm{nm}$ of $\mathrm{ZnO}$ thin film ground at $200 \mathrm{rpm}$ for $60 \mathrm{~min}$ using DI water solvent (inset (left) optical map image of total PL intensity obtained for 415-715 nm and (right) overall range averaged full spectrum). (g) Raman spectra of $\mathrm{ZnO}$ ground film prepared using DI water ground at $200 \mathrm{rpm}$ for $60 \mathrm{~min}$. (h) Raman spectra of different ZnO films ground (EG solvent) and unground: black, bulk sample; blue, ground at $200 \mathrm{rpm}$ for $10 \mathrm{~min}$; red, ground at $750 \mathrm{rpm}$ for $90 \mathrm{~min}$. (i) EDX spectrum of ZnO film using PBM nanoink ground at $600 \mathrm{rpm}$ for $10 \mathrm{~min}$ in EG solvent.

\subsection{Gas Sensing Results}

Figure 3 shows current (at $+2 \mathrm{~V}$ applied bias) vs. time and $I-V$ curves for $\mathrm{ZnO}$ thin film sensors formed using the PBM nanoinks. In Figure 3a, the current levels vs. time for a flow sequence of dry air/pure argon/dry air are shown (similar behavior was observed for nitrogen target gas environments). The time-dependent sensor behavior was observed upon exposure to a target gas atmosphere after reaching a minimum in pure dry air flow, whereby output current rises upon injection of the target gas source(s) and falls upon release of the gas (and re-exposure to dry air/oxygen). Accordingly, the resistance of the sensor underwent a decrease as it was exposed to a target and an increase as dry air was reintroduced. Initially, the sensor sample current (in ambient atmosphere) was observed to increase, and started to decrease as soon as dry air was introduced, indicating that the response of the $\mathrm{ZnO}$ gas thin film sensors are also strongly dependent on operating atmospheric humidity or RH. The humidity or moisture sensing ability of our $\mathrm{ZnO}$ films was confirmed by the resistance data shown in Figure 3b, which shows a large sensor response vs. RH. 
(a)

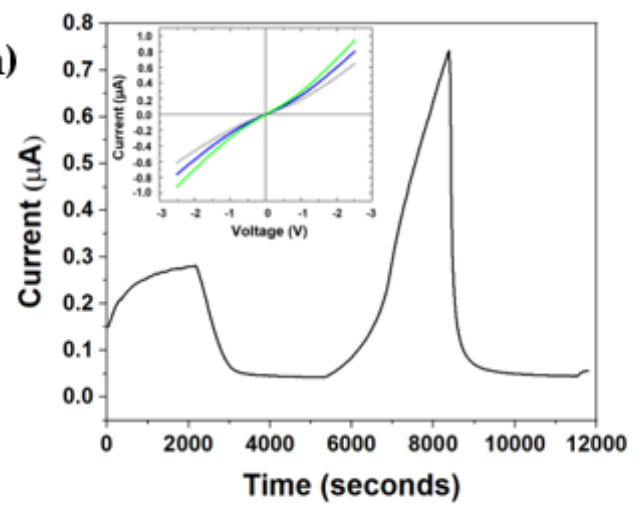

(c)

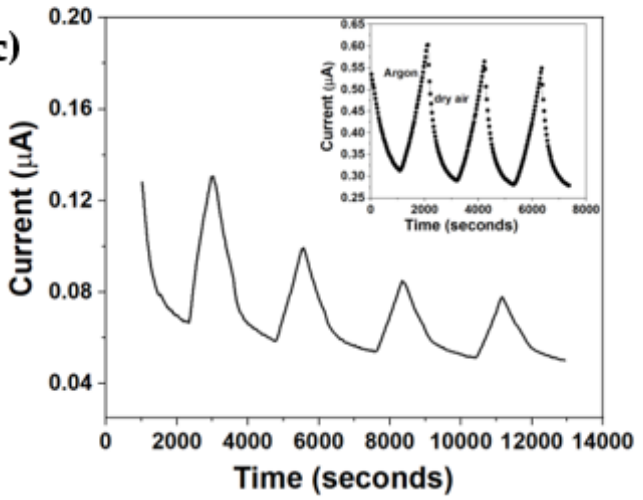

(e)

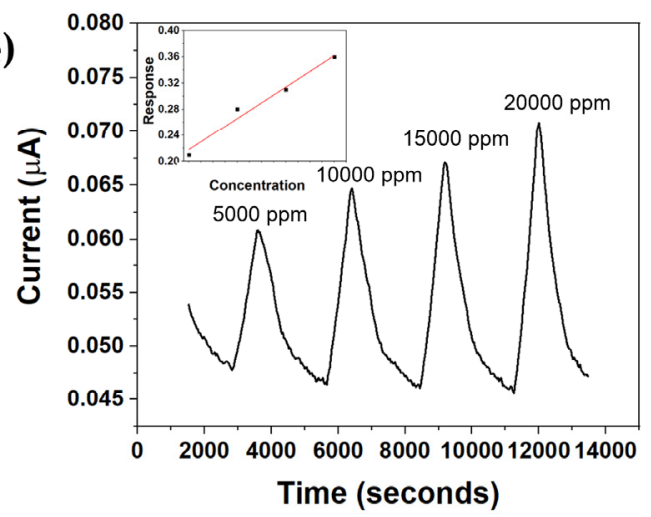

(b)

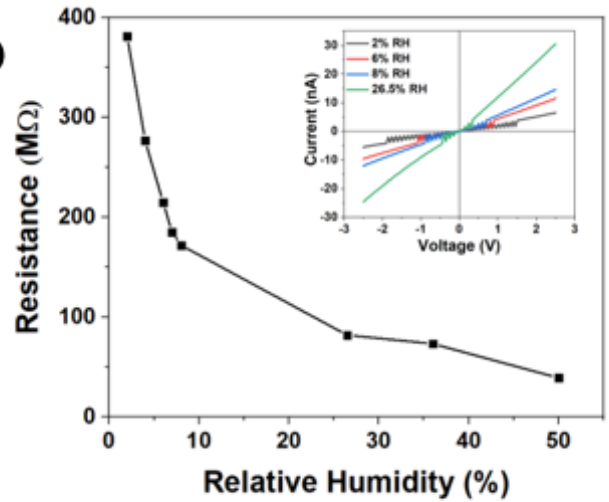

(d)

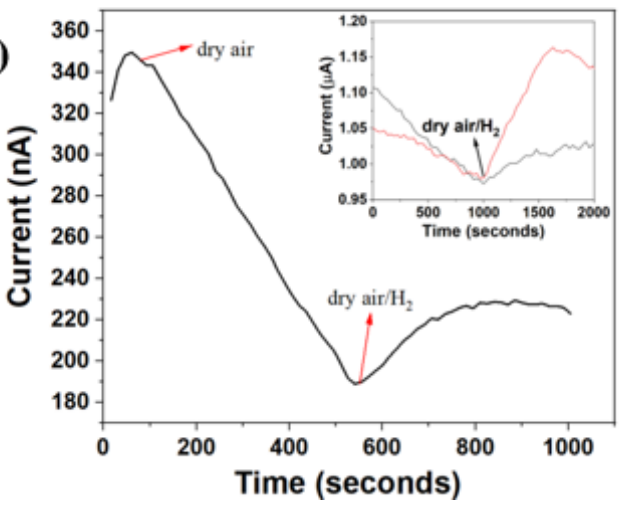

(f)

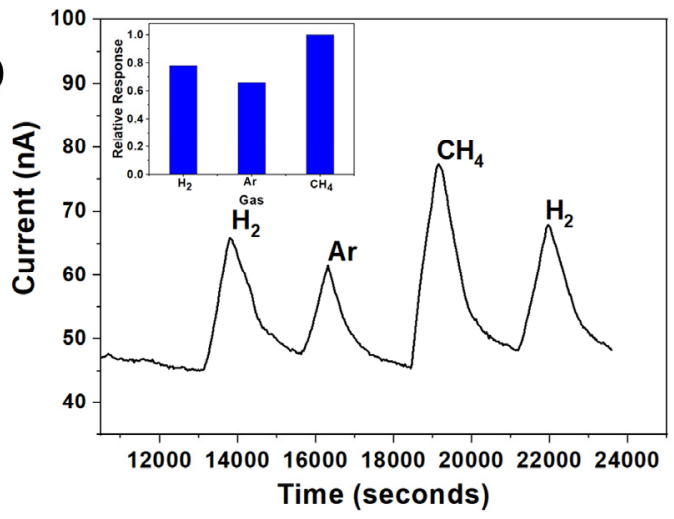

Figure 3. (a) Time dependence of sensor current upon exposure to dry air ( $2000 \mathrm{~s}$ mark) followed by pure argon gas ( $\sim 500 \mathrm{~s}$ mark) and then dry air again ( $\sim 8000 \mathrm{~s}$ mark) (all flows $500 \mathrm{sccm})$ for $\mathrm{ZnO}$ thin film sensors formed using PBM nanoinks ground for $10 \mathrm{~min}$ in EG (400 rpm). Inset shows $I-V$ plots as current increases near start of argon flow. (b) Resistance vs. $\mathrm{RH}$ for a $\mathrm{ZnO}$ thin film sensor formed using PBM nanoinks ground at $200 \mathrm{rpm}$ for $30 \mathrm{~min}$ in DI water. Inset shows individual $I-V$ plots for different humidity values. (c) Gas sensor (prepared using nanoinks ground at $400 \mathrm{rpm}$ for $10 \mathrm{~min}$ in EG solvent) showing approach to stable baseline vs. time during repeated exposure to $250 \mathrm{sccm}$ of $\mathrm{H}_{2}$ pulses. Inset shows sensor current vs. time for a similar sequence of on/off dry air/argon gas pulses for $\mathrm{ZnO}$ thin film sensor formed using PBM nanoinks ground for $10 \mathrm{~min}$ in EG (600 rpm). (d) Sensor current vs. time for $500 \mathrm{sccm}$ dry air followed by $400 \mathrm{sccm}$ dry air/100 sccm hydrogen (sensor formed using PBM nanoinks ground for 10 min in EG (600 rpm)). Inset shows current vs. time for $\mathrm{ZnO}$ sensor (prepared using nanoinks ground at $400 \mathrm{rpm}$ for $10 \mathrm{~min}$ in EG solvent) exposed to $450 \mathrm{sccm}$ dry air $/ 50 \mathrm{sccm}$ hydrogen (red curve) and $475 \mathrm{sccm}$ dry air $/ 25 \mathrm{sccm}$ hydrogen (black curve). (e) Current vs. time for ZnO thin film sensor (prepared using PBM nanoinks ground at $400 \mathrm{rpm}$ for $10 \mathrm{~min}$ in EG solvent) at different $\mathrm{H}_{2}$ gas concentrations indicated. Inset shows response as a function of gas concentration. (f) Current vs. time for $\mathrm{ZnO}$ thin film sensor (sample as in (e)) when exposed to different gases (hydrogen, argon, and methane). Inset shows relative response or selectivity to different target gas species.

The target gas response of our sensors was repeatable over multiple flow sequences; however, due to the size of the test quartz chamber and maximum flow rates used (in 
addition to the film thickness), it took some time to reach a stable baseline as displayed in Figure $3 \mathrm{c}$, which shows the sensor stabilizing after approximately $2.5 \mathrm{~h}$. Sensing with dry air as the carrier gas to balance the target species was also possible using our PBM nanoink sensors, as evidenced by the detection of hydrogen in Figure 3d, which shows that sensor current is proportional to target gas concentration. Further study of sensor response was performed for a sequence of hydrogen gas concentrations ranging from 5000 to 20,000 ppm (Figure 3e), which showed a linear response region (Figure 3e, inset) with a sensitivity of approximately $2.4 \times 10^{-2} \mathrm{ppm}^{-1}$. In addition, sensor selectivity was tested by exposure to the same concentration for different gas species (Figure $3 \mathrm{f}$ ), indicating a strong response to methane, followed by hydrogen and argon, which shows potential for selective gas sensing (Figure 3f, inset). Preferential adsorption of different gas molecules [86] likely leads to the sensor selectivity we observed at room temperature. Upon cycling back to the first gas pulse $\left(\mathrm{H}_{2}\right)$, the original sensor signal returned. In general, the gas sensor devices studied gave stable and reproducible responses that stayed within $25 \%$ of the original signal after several months.

The gas sensing response is usually defined as the ratio of resistances in two different gas atmospheres. In order to compare the performance of the gas sensors prepared using PBM nanoinks from different grinding conditions, the sensor response $[87,88]$ was calculated as

$$
\mathrm{S}=\frac{R_{a}-R_{g}}{R_{a}}
$$

where $R_{\mathrm{a}}$ and $R_{\mathrm{g}}$ are the sensor resistance in dry air and in the presence of target gas, respectively.

Figure 4 compares the effects of different grinding parameters (speed/time/solvent) on gas sensor response in the presence of argon target gas. It can be seen in Figure 4a that sensor response decreases with grinding speed beyond $400 \mathrm{rpm}$, possibly due to particle agglomeration and porosity variations (see Section 3.3). Response can also be seen to increase with grinding time, peaking near $30 \mathrm{~min}$ for a constant grinding speed of $200 \mathrm{rpm}$ (Figure $4 \mathrm{~b}$ ). Grinding of materials using high energy ball milling can produce both surface and bulk defects. It is possible that surface defects would enhance gas sensing performance by exposing adsorption sites, whereas bulk defects could limit the adsorption surface area [55]. The presence of surface defects such as $Z_{\mathrm{i}}-$ and $\mathrm{V}_{\mathrm{o}}$-related defects is indicated in the Raman data of Figure $2 \mathrm{~g}$ and $\mathrm{h}$ as grinding was increased. This could lead to a significant increase in gas sensor response because more oxygen molecules can be easily absorbed and ionized on the surface of $\mathrm{ZnO}$ [89]. However, grinding at a higher speed or for a longer time can also give rise to bulk defects; therefore, it is anticipated that there will be a point at which bulk defects arise during grinding, resulting in lower response, which is discussed further below.

(a)

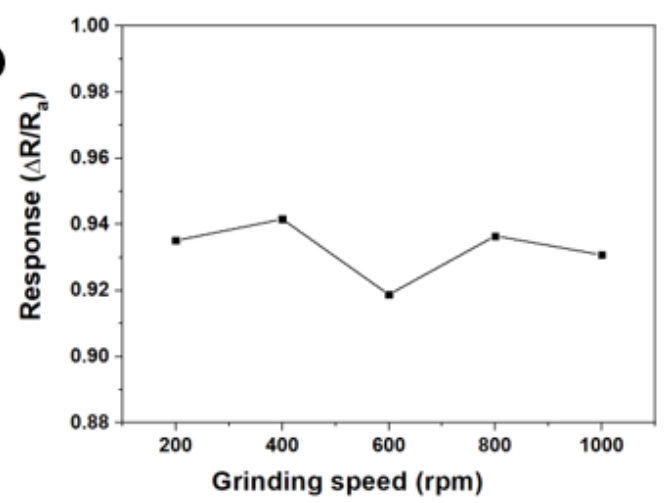

(b)

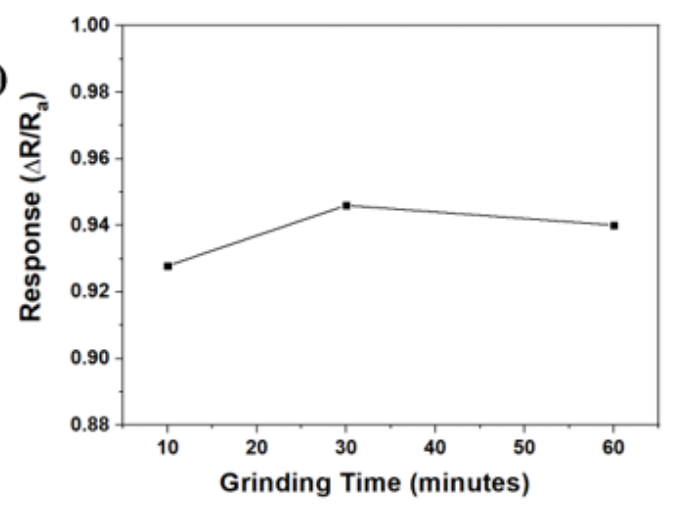

Figure 4. Response of different gas sensors made from ground PBM ZnO nanoinks towards argon gas. (a) Films prepared using EG solvent at different grinding speeds for constant grinding time of $10 \mathrm{~min}$. (b) Films prepared using DI water solvent at different grinding times for a constant grinding speed of $200 \mathrm{rpm}$. 


\subsection{Gas Sensing Mechanisms and Data Analysis}

An important parameter for gas sensing performance is the response/recovery time of the sensor. Response time is usually defined as the time required for a sensor to reach $90 \%$ of the total response signal, such as resistance or current upon exposure to the target gas [88]. On the other hand, recovery time is typically defined as the time required for a sensor to return to within $10 \%$ of the original signal upon removal of the target gas [88]. The response and recovery times depend upon diffusion paths (distance travelled by gas molecules through the nanoparticle sensing surface), film porosity, and particle agglomeration [13,90-92]. Based on the results shown in Figure 5a, gas sensors prepared from PBM nanoinks with lower grinding speeds have a faster response compared to sensors prepared from higher grinding speeds, with response time reaching a maximum near $600 \mathrm{rpm}$ before decreasing again at higher speeds. Similarly, increased grinding time also appears to increase response time, with a leveling off near 30 min observed (Figure 5c). Gas sensor recovery time generally increased with grinding speed up to $600 \mathrm{rpm}$ before dipping at $800 \mathrm{rpm}$ (Figure $5 \mathrm{~b}$ ), while a grinding time of approximately $30 \mathrm{~min}$ also displayed a dip (Figure 5d), indicating a faster sensor recovery. In general, to have an effective sensor that responds/recovers quickly, one should choose the optimal combination of nanoink grinding conditions, and based on Figure 5, this appears to occur for low to moderate grinding speeds (200-400 rpm) and moderate grinding times ( $30 \mathrm{~min})$ for the devices studied, or potentially higher grinding speeds $(\sim 800 \mathrm{rpm})$ with short grinding times ( 10 min).
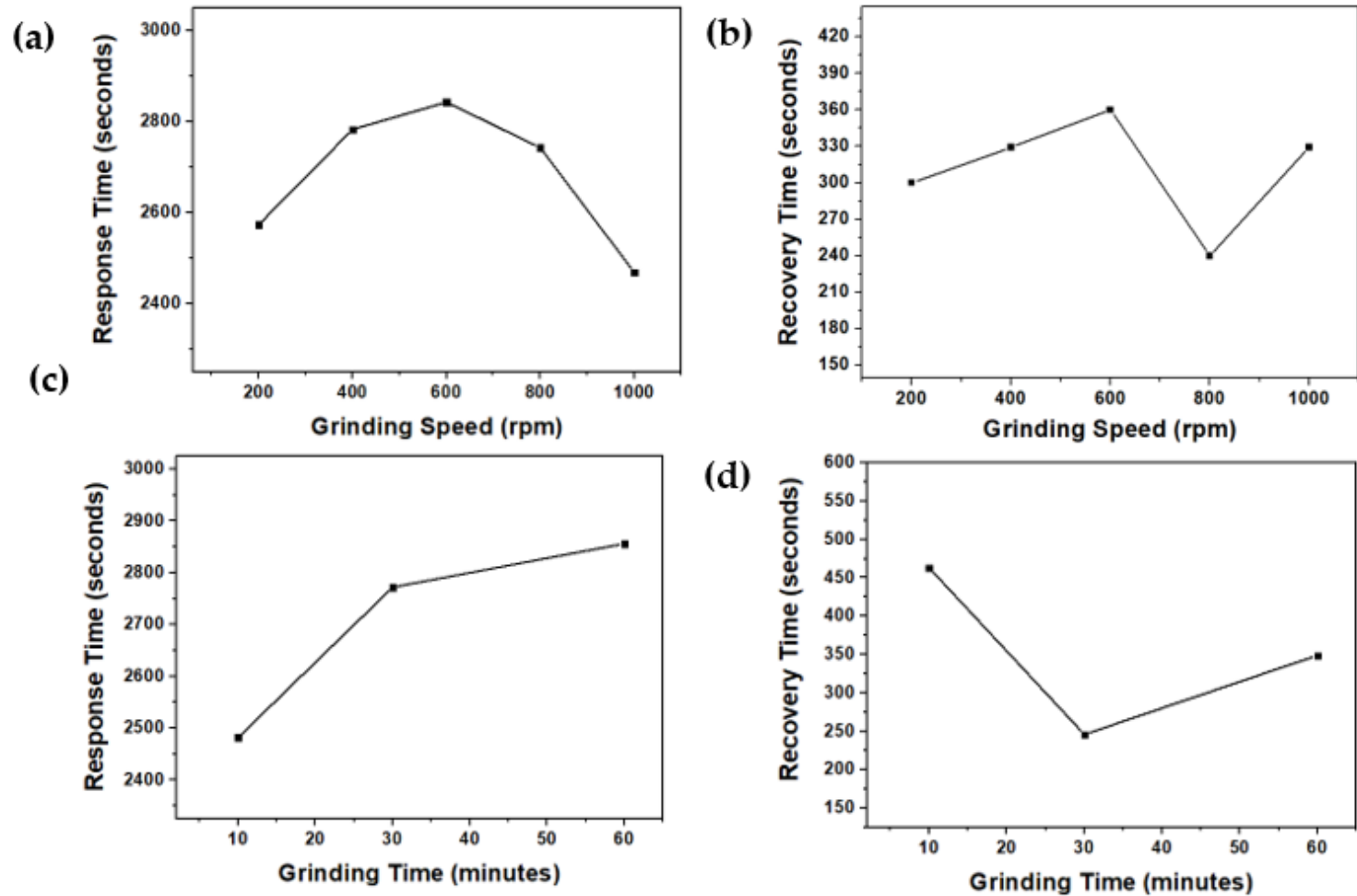

(d)

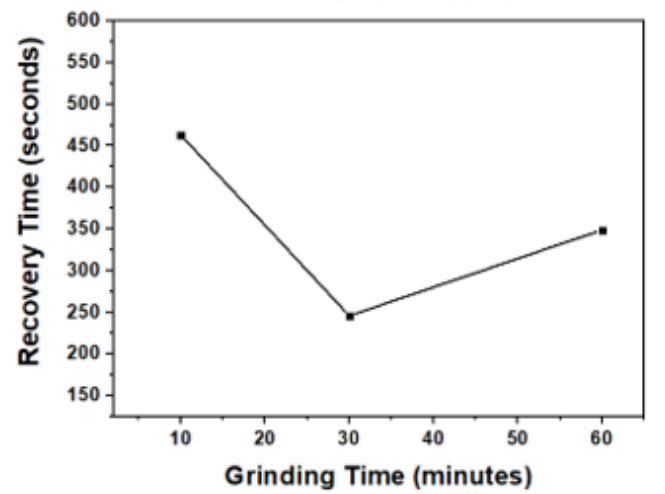

Figure 5. Test gas (argon) response time (a) and recovery time (b) of sensors prepared from $\mathrm{ZnO}$ nanoinks ground at different speeds for constant grinding time of $10 \mathrm{~min}$ using EG solvent. Response time (c) and recovery time (d) of sensors prepared from $\mathrm{ZnO}$ nanoinks ground at constant speed of $200 \mathrm{rpm}$ for different grinding times using DI water solvent. Note: Response/recovery time evaluation is constrained by gas flow rates (maximum 500-700 sccm), test chamber volume, and gas sensor film thickness used in the present study.

As mentioned earlier, the response of nanostructured thin film gas sensors is related to particle size and porosity. Figure 2c-e shows that grinding at a higher speed or for a longer time tends to result in smaller particle sizes. The smaller particle size is ac- 
companied by an increase in the total sensing surface area; thus, sensor performance is proportional to the decrease in grain size [13]. This explains the increase in sensor response (Figure 4) as grinding speed approaches $400 \mathrm{rpm}$ and grinding time reaches $30 \mathrm{~min}$. As particle size decreases further $(<200 \mathrm{~nm})$, it is possible that the nanoparticles suffer from increased agglomeration, which reduces the effective surface area and thus the free surface energy [93-95] (in addition, a large particle size dispersion as in the $600 \mathrm{rpm}$ sample of Figure $2 \mathrm{~d}$ may exacerbate this effect). The influence of agglomeration is consistent with decreased porosity observed for the samples made with nanoinks milled at a higher rpm (see Figure 6a) [96]. Lower porosity could also explain the faster response/recovery times observed for some samples in Figure 5. Further to the material characterization data in Section 3.1, grinding of the $\mathrm{ZnO}$ material eventually leads to an increase in surface and bulk defects. In general, the defect density on the surface is considered higher than in the bulk [97]. Surface defects function as (i) charge carrier traps and (ii) adsorption sites improving the electron-hole separation [98]. Bulk defects, on the other hand, serve as recombination sites [99]. Thus, the influence of grinding on the gas sensing behavior is dependent on the ratio of bulk-to-surface defects. Initially, as the grinding time/speed increases, the ratio of bulk-to-surface defects decreases, which can be attributed to an increase in the total surface area leading to comparatively higher surface defects. However, based on our results at higher grinding speeds and for longer times, this ratio seems to increase due to the formation of excess bulk defects, which may be attributed to bulk crystal distortion caused by excess mechanical attrition.

(a)

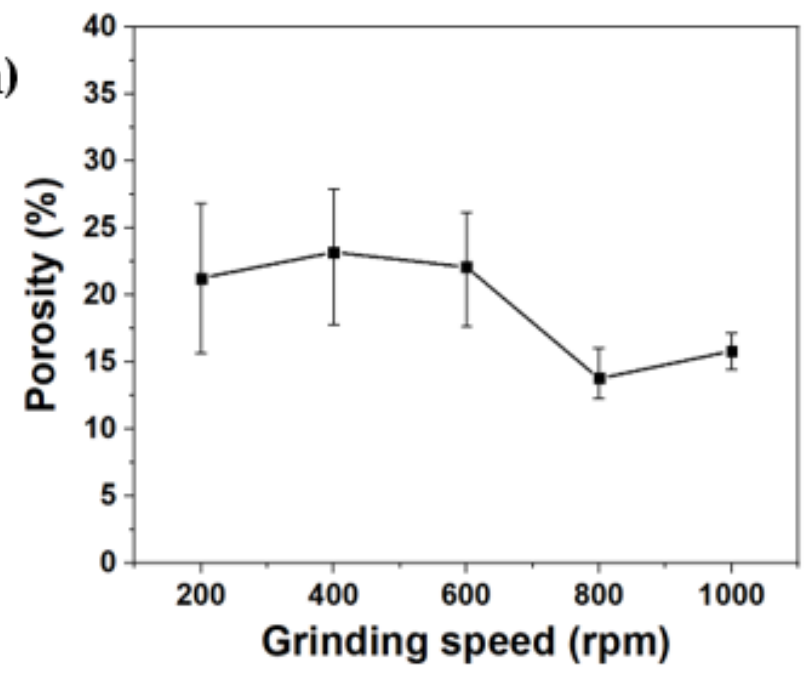

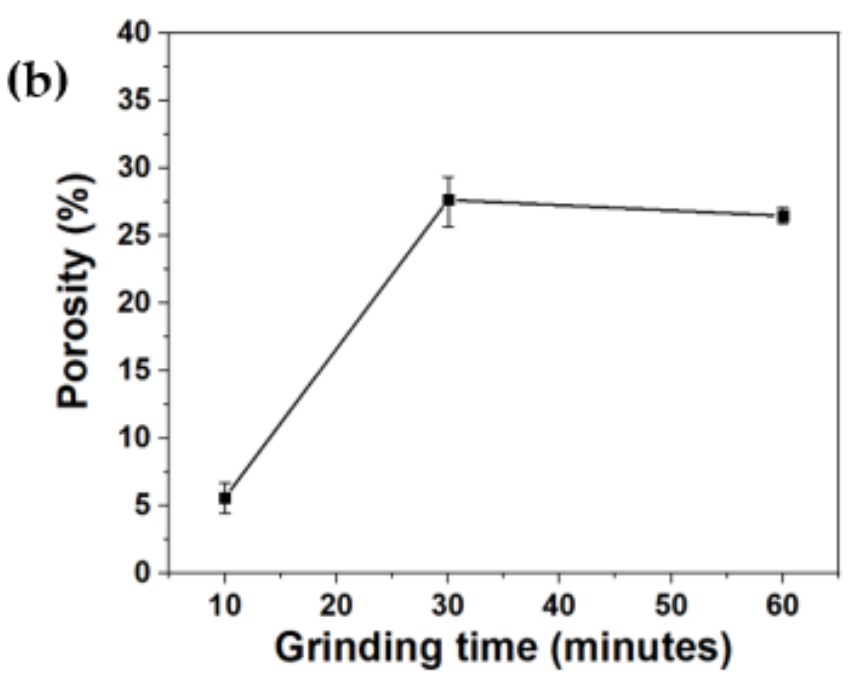

Figure 6. Porosity of sensors prepared using ZnO nanoinks obtained from AFM and SEM data. (a) Sensor prepared using EG solvent for different grinding speeds at constant grinding time of $10 \mathrm{~min}$. (b) Sensor prepared from DI water solvent at different grinding times for constant grinding speed of $200 \mathrm{rpm}$.

Since $\mathrm{ZnO}$ is a chemiresistive sensing material [29], the sensor response mechanism is influenced by the gas-surface absorption-desorption process, surface diffusion-reaction, and redox reactions between active species on the sensor surfaces [100]. In addition, defects of nanostructured $\mathrm{ZnO}$ such as oxygen vacancies (see Raman data, Figure 2) can act as electron donors, which enhances conductivity and promotes gas sensing performance $[19,90]$. Grinding in the presence of solvents during PBM can also result in surface modification [101], since ball milling is an energy intensive process. The energy from the high speed impact of the beads can result in the formation of reactive radicals [101]. The grinding media, therefore, can influence the baseline resistivity of the $\mathrm{ZnO}$ nanostructured films $[29,102,103]$.

The sensing mechanisms in our fabricated sensors likely depend on surface interaction and charge transfer between adsorbed gas species, which results in variation of sensor resistance (or conductance) [104]; it has been reported that $\mathrm{O}_{2}{ }^{-}$species will be present at 
$\mathrm{ZnO}$ film surfaces at room temperature $[105,106]$, which results in an electron-depletion layer (barrier layer) on the outer surface of the $\mathrm{ZnO}$ in air. Between grains, the merging of the two depletion regions creates a Schottky barrier, the magnitude of which determines the conductivity of the materials [96]. The reaction between the adsorbed oxygen species with adsorbed gas molecules can modify the height of the Schottky barrier, resulting in the variation of sensor resistivity; in dark conditions, when the $\mathrm{ZnO}$ surface is exposed to an air environment, electrons from the $\mathrm{ZnO}$ conduction band ionize atmospheric oxygen to produce negative oxygen ions at the surface of the nanostructured film (Equation (2)), thereby creating a low conductivity depletion layer near the surface [107].

$$
\mathrm{O}_{2} \text { (gas) }+\mathrm{e}^{-} \rightarrow \mathrm{O}_{2}^{-} \text {(ads), }
$$

When light with higher energy than the bandgap of $\mathrm{ZnO}$ is incident, electron-hole pairs will be generated. Holes produced by the light absorption migrate to the surface along the potential slope created by band bending and neutralize the negatively charged adsorbed oxygen ions (Equation (3)), which are then desorbed, while the photogenerated electrons reduce the width of the depletion layer, thereby increasing conductivity [107].

$$
\mathrm{h}^{+}+\mathrm{O}_{2}^{-} \text {(ads) } \rightarrow \mathrm{O}_{2} \text { (gas) }
$$

Thus, conduction in dark and photoconduction of the $\mathrm{ZnO}$ films are strongly dependent on the ambient gas conditions and oxidizing atmosphere. In addition, $\mathrm{RH}$, defined as the amount of water vapor in air, expressed as a percentage of the maximum amount that the air could hold at a given temperature, can also strongly impact a metal oxide surface [108] and thus alter the sensor response [109-111]. Water molecules adsorbed on the surface tend to dope $\mathrm{ZnO}$ with electrons and/or displace previously adsorbed ionized oxygen, releasing electrons back to the conduction band (i.e., the reverse of Equation (2)) [110]. In both cases, sensor conductivity increases as consistent with Figure 3b.

For the $\mathrm{ZnO}$ thin film gas sensors based on PBM nanoinks reported here, the ultimate performance likely depends on a combination of grain size, porosity, and surface-to-bulk defect ratio within the films. The results from porosity (Figure 6) indicate that there is high surface area in sensors based on PBM nanoinks, peaking around a grinding speed of $400 \mathrm{rpm}$ and grinding time of $30 \mathrm{~min}$, which ultimately creates more active sites and gas diffusion channels and hence improves sensing signal magnitude.

To probe the gas sensor performance further, we examined the effect of operating temperature on sensor response; thermally activated processes can impact reaction kinetics, carrier concentration, and mobility on/near the sensing surface, all of which affect gas sensor detection response and dynamic behavior [112]. Figure 7a shows temperaturedependent sensor response data indicating optimal operation near $100{ }^{\circ} \mathrm{C}$, followed by a decline at higher temperatures, consistent with prior work using metal oxides [113]. Similarly, a shortening of response and recovery times (Figure $7 \mathrm{~b}$ ) at elevated temperatures is due to reduction in activation energy required for surface reactions, i.e., faster absorption and desorption occurs on the surface of the $\mathrm{ZnO}$, leading to shorter response/recovery time [114].

Table 1 summarizes data for $\mathrm{ZnO}$ gas sensors fabricated using various synthesis techniques, including ball milling, and their response to different gas species. 
(a)

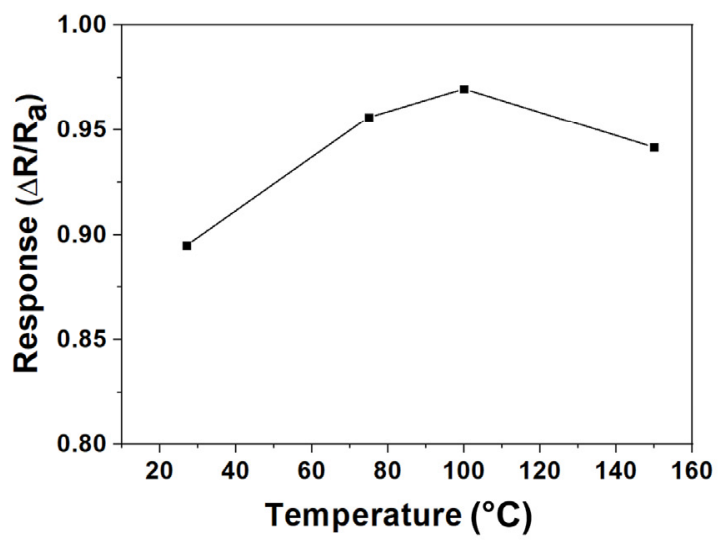

(b)

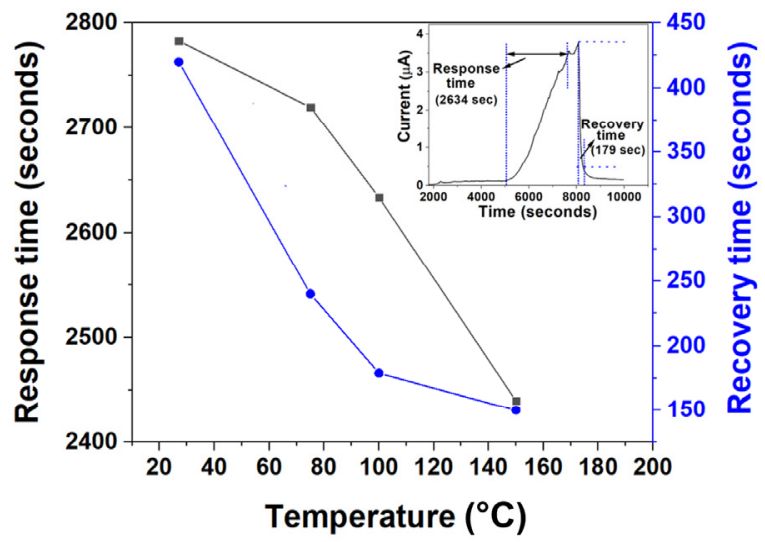

Figure 7. Effect of temperature on sensor response. (a) Response for sensors prepared from $\mathrm{ZnO}$ nanoinks ground at $600 \mathrm{rpm}$ for $10 \mathrm{~min}$ using EG solvent. (b) Response and recovery time. The inset shows the time dependence of sensor current upon exposure to dry air followed by argon test gas at $100{ }^{\circ} \mathrm{C}$.

Table 1. Brief summary of gas sensor response for $\mathrm{ZnO}$-based devices operating at different temperatures.

\begin{tabular}{|c|c|c|c|c|c|}
\hline Material & Target Gas & LOD & Response/Temperature & Response Time/Recovery Time & References \\
\hline Present work & $\mathrm{H}_{2}(5000 \mathrm{ppm})$ & $500 \mathrm{ppm}$ & $21 \%{ }^{\mathrm{b}} / \mathrm{RT}$ & - & - \\
\hline $\mathrm{CuO}$ coated $\mathrm{ZnO}$ using ball milling method & $\mathrm{H}_{2}(200 \mathrm{ppm})$ & - & $\sim 15^{\mathrm{a}} / 300^{\circ} \mathrm{C}$ & - & [115] \\
\hline $\mathrm{ZnO}$ nanotube using chemical etching process & $\mathrm{H}_{2}(500 \mathrm{ppm})$ & $5 \mathrm{ppm}$ & $\sim 29.6 \%$ b $/ \mathrm{RT}$ & $\sim 540 \mathrm{~s} /-$ & [116] \\
\hline $\mathrm{SnO}_{2}$-doped $\mathrm{ZnO}$ using ball milling method & $\mathrm{CO}(200 \mathrm{ppm})$ & - & $\sim 5^{\mathrm{a}} / 450^{\circ} \mathrm{C}$ & - & [66] \\
\hline $\mathrm{ZnO}-\mathrm{CuO}$ composite via ball milling process & $\mathrm{CO}(200 \mathrm{ppm})$ & - & $\sim 12.2^{\mathrm{a} /} / 180^{\circ} \mathrm{C}$ & - & {$[117]$} \\
\hline Pt-doped $\mathrm{ZnO}$ using RF sputtering & $\mathrm{H}_{2}(1000 \mathrm{ppm})$ & $250 \mathrm{ppm}$ & $\sim 5.5^{\mathrm{a}} / 200^{\circ} \mathrm{C}$ & $36 \mathrm{~s} / 112 \mathrm{~s}$ & [118] \\
\hline $\mathrm{ZnO}$ nanowires by thermal evaporation & $\mathrm{H}_{2}(100 \mathrm{ppm})$ & $50 \mathrm{ppm}$ & $\sim 5.5^{\mathrm{a}} / 200^{\circ} \mathrm{C}$ & $30 \mathrm{~s} /-$ & [119] \\
\hline
\end{tabular}

\section{Conclusions}

In summary, chemiresistive $\mathrm{ZnO}$ thin film gas sensors operating at room temperature were fabricated using PBM nanoinks and doctor blading for the effective detection of gas species, including dry air/oxygen, argon, nitrogen, hydrogen, and methane, in addition to atmospheric humidity. By varying grinding parameters, nanoparticle structure and electrical characteristics of the resultant films could be optimized for efficient gas sensing. The response of different fabricated gas sensors versus milling speed and time revealed that nanostructured films made using $\mathrm{ZnO}$ nanoinks milled at $400 \mathrm{rpm}$ for $30 \mathrm{~min}$ produced the best combination of sensor signal magnitude and dynamic behavior (time response), and further performance enhancement was observed up to temperatures of $100{ }^{\circ} \mathrm{C}$. Future studies could examine the effect of different materials and grinding solvents on $\mathrm{ZnO}$ PBM nanoink-based sensors along with different grinding times/speeds to refine the optimal gas sensor structure as a function of film thickness. In addition, sensing different solvent vapors (acetone, IPA, ethanol, etc.) and humidity along with multiple gases for multiplexed E-nose applications $[120,121]$ should all be feasible using the low-cost PBM nanoink thin film gas sensor approach presented.

Author Contributions: Conceptualization, R.S. and C.P.; methodology, R.S., P.D. and T.K.; investigation, P.D. and R.S.; data curation, A.V.; writing—original draft preparation, R.S. and P.D.; writingreview and editing, C.P.; supervision, C.P. All authors have read and agreed to the published version of the manuscript.

Funding: This work was funded in part by Natural Sciences and Engineering Research Council of Canada and the Canada Foundation for Innovation.

Institutional Review Board Statement: Not applicable.

Informed Consent Statement: Not applicable.

Data Availability Statement: Not applicable. 
Acknowledgments: We thank Sahil Dawka for assisting with sample fabrication; the UBC Bioimaging Facility for SEM, EDX, and PL spectroscopy; and Western Economic Diversification Canada and A.G Brolo for Raman spectroscopy. T. Kumar was supported by the MITACS Globalink program.

Conflicts of Interest: The authors declare no conflict of interest.

\section{References}

1. Fernando, R.H. Nanocomposite and Nanostructured Coatings: Recent Advancements. In Nanotechnology Applications in Coatings; American Chemical Society: Washington, DC, USA, 2009; pp. 2-21.

2. Levashov, E.A.; Shtansky, D.V. Multifunctional nanostructured films. Russ. Chem. Rev. 2007, 76, 463-470. [CrossRef]

3. Kumar, R.; Kumar, G.; Al-Dossary, O.; Umar, A. ZnO nanostructured thin films: Depositions, properties applications-A review. Mater. Express 2015, 5, 3-23. [CrossRef]

4. Rao, T.P.; Santhosh Kumar, M.C. Effect of thickness on structural, optical and electrical properties of nanostructured ZnO thin films by spray pyrolysis. Appl. Surf. Sci. 2009, 255, 4579-4584. [CrossRef]

5. Mao, S.; Lu, G.; Chen, J. Nanocarbon-based gas sensors: Progress and challenges. J. Mater. Chem. A 2014, 2, 5573-5579. [CrossRef]

6. Ali, S.; Gupta, A.; Shafiei, M.; Langford, S.J. Recent Advances in Perylene Diimide-Based Active Materials in Electrical Mode Gas Sensing. Chemosensors 2021, 9, 30. [CrossRef]

7. Mao, S.; Cui, S.; Yu, K.; Wen, Z.; Lu, G.; Chen, J. Ultrafast hydrogen sensing through hybrids semiconducting single-walled carbon nanotubes tin oxide nanocrystals. Nanoscale 2012, 4, 1275-1279. [CrossRef]

8. Ali, S.; Jameel, M.A.; Gupta, A.; Langford, S.J.; Shafiei, M. Capacitive humidity sensing performance of naphthalene diimide derivatives at ambient temperature. Synth. Met. 2021, 275, 116739. [CrossRef]

9. Kong, J.; Franklin, N.R.; Zhou, C.; Chapline, M.G.; Peng, S.; Cho, K.; Dai, H. Nanotube Molecular Wires as Chemical Sensors. Science 2000, 287, 622-625. [CrossRef] [PubMed]

10. Huang, X.-J.; Choi, Y.-K. Chemical sensors based on nanostructured materials. Sens. Actuators B 2007, 122, 659-671. [CrossRef]

11. Dey, A. Semiconductor metal oxide gas sensors A Review. Mater. Sci. Eng. B 2018, 229, 206-217. [CrossRef]

12. Jiménez-Cadena, G.; Riu, J.; Rius, F.X. Gas sensors based on nanostructured materials. Analyst 2007, 132, 1083-1099. [CrossRef]

13. Vollath, D. Nanomaterials an Introduction to Synthesis, Properties and Applications, 2nd ed.; Wiley-VCH Verlag GmbH \& Co. KGaA: Weinheim, Germany, 2013.

14. Mirzaei, A.; Kim, J.-H.; Kim, H.W.; Kim, S.S. How shell thickness can affect the gas sensing properties of nanostructured materials: Survey of literature. Sens. Actuators B 2018, 258, 270-294. [CrossRef]

15. Eranna, G.; Joshi, B.C.; Runthala, D.P.; Gupta, R.P. Oxide Materials for Development of Integrated Gas Sensors-A Comprehensive Review. Crit. Rev. Solid State Mater. Sci. 2004, 29, 111-188. [CrossRef]

16. Sun, Y.-F.; Liu, S.-B.; Meng, F.-L.; Liu, J.-Y.; Jin, Z.; Kong, L.-T.; Liu, J.-H. Metal oxide nanostructures and their gas sensing properties: A review. Sensors 2012, 12, 2610-2631. [CrossRef]

17. Cerjak, H. Nanomaterials: An introduction to synthesis, properties and applications. Mater. Technol. 2009, 24, 74. [CrossRef]

18. Koo, W.-T.; Cho, H.-J.; Kim, D.-H.; Kim, Y.H.; Shin, H.; Penner, R.M.; Kim, I.-D. Chemiresistive Hydrogen Sensors: Fundamentals, Recent Advances, and Challenges. ACS Nano 2020, 14, 14284-14322. [CrossRef] [PubMed]

19. Li, Z.; Liu, X.; Zhou, M.; Zhang, S.; Cao, S.; Lei, G.; Lou, C.; Zhang, J. Plasma-induced oxygen vacancies enabled ultrathin ZnO films for highly sensitive detection triethylamine. J. Hazard. Mater. 2021, 415, 125757. [CrossRef]

20. Hastir, A.; Kohli, N.; Singh, R.C. Ag doped ZnO Nanowires as highly sensitive ethanol gas sensor. Mater. Today:. Proc. 2017, 4, 9476-9480. [CrossRef]

21. Majhi, S.M.; Rai, P.; Yu, Y.-T. Facile Approach to Synthesize Au@ZnO Core-Shell Nanoparticles and TheirApplication for Highly Sensitive and Selective Gas Sensors. ACS Appl. Mater. Interfaces 2015, 7, 9462-9468. [CrossRef]

22. Guo, J.; Zhang, J.; Zhu, M.; Ju, D.; Xu, H.; Cao, B. High performance gas sensor based on ZnO nanowires functionalized by Au nanoparticles. Sens. Actuators B 2014, 199, 339-345. [CrossRef]

23. Barsan, N.; Koziej, D.; Weimar, U. Metal oxide- based gas sensor research: How to? Sens. Actuators B 2007, 121, 18-35. [CrossRef]

24. Lu, H.F.; Li, F.; Liu, G.; Chen, Z.-G.; Wang, D.-W.; Fang, H.-T.; Lu, G.Q.; Jiang, Z.H.; Cheng, H.-M. Amorphous TiO2 nanotube arrays for low-temperature oxygen sensors. Nanotechnology 2008, 19, 405504. [CrossRef] [PubMed]

25. Tiburcio-Silver, A.; Sánchez-Juárez, A. $\mathrm{SnO}_{2}$ : Ga thin films as oxygen gas sensor. Mater. Sci. Eng., B. 2004, 110, 268-271. [CrossRef]

26. Gupta, S.; Joshi, A.; Kaur, M. Development of gas sensors using ZnO nanostructures. J. Chem. Sci. 2010, 122, 57-62. [CrossRef]

27. Chaabouni, F.; Abaab, M.; Rezig, B. Metrological characteristics of ZnO oxygen sensor at room temperature. Sens. Actuators B 2004, 100, 200-204. [CrossRef]

28. Khosravi, Y.; Sasar, M.; Abdi, Y. Light-induced oxygen sensing using ZnO/GO based gas sensor. Mater. Sci. Semicond. Process. 2018, 85, 9-14. [CrossRef]

29. Zhu, L.; Zeng, W. Room-temperature gas sensing of ZnO-based gas sensor: A review. Sens. Actuators A 2017, $267,242-261$. [CrossRef]

30. Mukae, K.; Tsuda, K.; Nagasawa, I. Capacitance-vs-voltage characteristics of ZnO varistors. J. Appl. Phys. 1979, 50, 4475-4476. [CrossRef]

31. Dongale, T.D.; Khot, K.V.; Mali, S.S.; Patil, P.S.; Gaikwad, P.K.; Kamat, R.K.; Bhosale, P.N. Development of Ag/ZnO/FTO thin film memristor using aqueous chemical route. Mater. Sci. Semicond. Process. 2015, 40, 523-526. [CrossRef] 
32. Biswas, C.; Ma, Z.; Zhu, X.; Kawaharamura, T.; Wang, K.L. Atmospheric growth of hybrid ZnO thin films for inverted polymer Solar cells. Sol. Energy Mater. Sol. Cells 2016, 157, 1048-1056. [CrossRef]

33. Choi, M.-Y.; Choi, D.; Jin, M.-J.; Kim, I.; Kim, S.-H.; Choi, J.-Y.; Lee, S.Y.; Kim, J.M.; Kim, S.-W. Mechanically powered transparent flexible charge-generating nanodevices with piezoelectric $\mathrm{ZnO}$ nanorods. Adv. Mater. 2009, 21, 2185-2189. [CrossRef]

34. Ryu, Y.; Lee, T.-S.; Lubguban, J.A.; White, H.W.; Kim, B.-J.; Park, Y.-S.; Youn, C.-J. Next generation of oxide photonic devices: ZnO-based ultraviolet light emitting diodes. Appl. Phys. Lett. 2006, 88, 241108. [CrossRef]

35. Wang, X.; Summers, C.J.; Wang, Z.L. Large-scale hexagonal patterned growth of aligned ZnO nanorods for nano-optoelectronics and nanosensor arrays. Nano Lett. 2004, 4, 423-426. [CrossRef]

36. Mao, Y.Z.; Ma, S.Y.; Li, W.Q.; Luo, J.; Cheng, L.; Gengzang, D.J.; Xu, X.L. Synthesis of porous small-sized ZnO nanoparticles and their gas-sensing performance. Mater. Lett. 2015, 157, 151-154. [CrossRef]

37. Liewhiran, C.; Phanichphant, S. Doctor-bladed thick films of flame-made Pd/ZnO nanoparticles for ethanol sensing. Curr. Appl Phys. 2008, 8, 336-339. [CrossRef]

38. Koshizaki, N.; Oyama, T. Sensing characteristics of ZnO-based NOx sensor. Sens. Actuators B 2000, 66, 119-121. [CrossRef]

39. Khan, S.B.; Faisal, M.; Rahman, M.M.; Jamal, A. Low-temperature growth of ZnO nanoparticles: Photocatalyst and acetone sensor. Talanta 2011, 85, 943-949. [CrossRef]

40. Wagh, M.S.; Jain, G.H.; Patil, D.R.; Patil, S.A.; Patil, L.A. Modified zinc oxide thick film resistors as $\mathrm{NH}_{3}$ gas sensor. Sens. Actuators B 2006, 115, 128-133. [CrossRef]

41. Ryu, H.-W.; Park, B.-S.; Akbar, S.A.; Lee, W.-S.; Hong, K.-J.; Seo, Y.-J.; Shin, D.-C.; Park, J.-S.; Choi, G.-P. ZnO sol-gel derived porous film for CO gas sensing. Sens. Actuators B 2003, 96, 717-722. [CrossRef]

42. Li, B.S.; Liu, Y.C.; Chu, Z.S.; Shen, D.Z.; Lu, Y.M.; Zhang, J.Y.; Fan, X.W. High quality ZnO thin films grown by plasma enhanced chemical vapor deposition. J. Appl. Phys. 2002, 91, 501-505. [CrossRef]

43. Lou, C.; Wang, K.; Mei, H.; Xie, J.; Zheng, W.; Liu, X.; Zhang, J. ZnO nanoarrays via a thermal decomposition-deposition method for sensitive and selective $\mathrm{NO}_{2}$ detection. Cryst. Eng. Comm. 2021, 23, 3654-3663. [CrossRef]

44. Xu, Y.; Zheng, W.; Liu, X.; Zhang, L.; Zheng, L.; Yang, C.; Pinna, N.; Zhang, J. Platinum single atoms on tin oxide ultrathin films for extremely sensitive gas detection. Mater. Horiz. 2020, 7, 1519-1527. [CrossRef]

45. Stambolova, I.; Konstantinov, K.; Vassilev, S.; Peshev, P.; Tsacheva, T. Lanthanum doped $\mathrm{SnO}_{2}$ and $\mathrm{ZnO}$ thin films sensitive to ethanol and humidity. Mater. Chem. Phys. 2000, 63, 104-108. [CrossRef]

46. Ohshima, T.; Thareja, R.K.; Yamagata, Y.; Ikegami, T.; Ebihara, K.; Narayan, J. Laser-ablated plasma for deposition of ZnO thin films on various substrates. Sci. Technol. Adv. Mater. 2001, 2, 517-523. [CrossRef]

47. Erol, A.; Okur, S.; Comba, B.; Mermer, Ö.; Arıkan, M.Ç. Humidity sensing properties of ZnO nanoparticles synthesized by sol-gel process. Sens. Actuators B 2010, 145, 174-180. [CrossRef]

48. Omerovic, N.; Radovic, M.; Savic, S.M.; Katona, J. Preparation of $\mathrm{TiO}_{2}$ and $\mathrm{ZnO}$ dispersions for inkjet printing of flexible sensing devices. Process. Appl. Ceram. 2018, 12, 326-334. [CrossRef]

49. Liu, H.-Y.; Kong, H.; Ma, X.-M.; Shi, W.-Z. Microstructure and electrical properties of ZnO-based varistors prepared by high-energy ball milling. J. Mater. Sci. 2007, 42, 2637-2642. [CrossRef]

50. Takehana, M.; Nishino, T.; Sugawara, K.; Sugawara, T. Preparation of zinc oxide varistor by a wet chemical method. Mater. Sci. Eng. B 1996, 41, 186-189. [CrossRef]

51. Salah, N.; Habib, S.S.; Khan, Z.H.; Memic, A.; Azam, A.; Alarfaj, E.; Zahed, N.; Al-Hamedi, S. High energy Ball milling technique for $\mathrm{ZnO}$ nanoparticles as antibacterial material. Int. J. Nanomed. 2011, 6, 863. [CrossRef] [PubMed]

52. Qi, Q.; Zhang, T.; Yu, Q.; Wang, R.; Zeng, Y.; Liu, L.; Yang, H. Properties of humidity sensing ZnO nanorods-base sensor fabricated by Screen printing. Sens. Actuators B 2008, 133, 638-643. [CrossRef]

53. Wang, C.-T.; Huang, K.-Y.; Lin, D.T.; Liao, W.-C.; Lin, H.-W.; Hu, Y.-C. A flexible proximity sensor fully fabricated inkjet printing. Sensors 2010, 10, 5054-5062. [CrossRef]

54. Deng, Y.; Peng, E.; Shao, Y.; Xiao, Z.; Dong, Q.; Huang, J. Scalable fabrication of efficient organolead trihalide perovskite solar cells with doctor-bladed active layers. Energy Environ. Sci. 2015, 8, 1544-1550. [CrossRef]

55. Giri, P.K.; Bhattacharyya, S.; Singh, D.K.; Kesavamoorthy, R.; Panigrahi, B.K.; Nair, K.G.M. Correlation between microstructure and optical properties of $\mathrm{ZnO}$ nanoparticles synthesized by ball milling. J. Appl. Phys. 2007, 102, 093515. [CrossRef]

56. Fokina, E.; Budim, N.; Kochnev, V.; Chernik, G. Planetary mills of periodic and continuous action. J. Mater. Sci. 2004, 39, 5217-5221. [CrossRef]

57. Mio, H.; Kano, J.; Saito, F. Scale-up method of planetary ball Mill. Chem. Eng. Sci. 2004, 59, 5909-5916. [CrossRef]

58. Baláž, P.; Achimovičová, M.; Baláž, M.; Billik, P.; Cherkezova-Zheleva, Z.; Criado, J.M.; Delogu, F.; Dutková, E.; Gaffet, E.; Gotor, F.J.; et al. Hallmarks of mechanochemistry: From nanoparticles to technology. Chem. Soc. Rev. 2013, 42, 7571-7637. [CrossRef] [PubMed]

59. Bruckmann, A.; Krebs, A.; Bolm, C. Organocatalytic reactions: Effects of ball milling, microwave and ultrasound irradiation. Green Chem. 2008, 10, 1131-1141. [CrossRef]

60. Sapkota, R.; Zou, J.; Dawka, S.; Bobak, J.E.; Papadopoulos, C. Multifunctional thin film coatings formed via nanogrinding. Appl. Nanosci. 2018, 8, 1437-1444. [CrossRef]

61. Huang, L.; Kramer, G.; Wieldraaijer, W.; Brands, D.; Poels, E.; Castricum, H.; Bakker, H. Methanol synthesis over Cu/ZnO catalysts prepared by ball milling. Catal. Lett. 1997, 48, 55-59. [CrossRef] 
62. Yong, H.E.; Krishnamoorthy, K.; Hyun, K.T.; Kim, S.J. Preparation of ZnO nanopaint for marine antifouling applications. J. Ind. Eng. Chem. 2015, 29, 39-42. [CrossRef]

63. Yu, M.; Shao, D.; Lu, F.; Sun, X.; Sun, H.; Hu, T.; Wang, G.; Sawyer, S.; Qiu, H.; Lian, J. ZnO/graphene nanocomposite fabricated by high energy ball milling with greatly enhanced lithium storage capability. Electrochem. Commun. 2013, 34, 312-315. [CrossRef]

64. Radoi, R.; Fernández, P.; Piqueras, J.; Wiggins, M.S.; Solis, J. Luminescence properties of mechanically milled and laser irradiated ZnO. Nanotechnology 2003, 14, 794-798. [CrossRef]

65. Xie, C.; Xiao, L.; Hu, M.; Bai, Z.; Xia, X.; Zeng, D. Fabrication and formaldehyde gas-sensing property of $\mathrm{ZnO}-\mathrm{MnO}_{2}$ coplanar gas sensor arrays. Sens. Actuators B 2010, 145, 457-463. [CrossRef]

66. Choi, J.D.; Choi, G.M. Electrical and CO gas sensing properties of layered ZnO-CuO Sensor. Sens. Actuators B 2000, 69, 120-126. [CrossRef]

67. Chen, H.; Liu, Y.; Xie, C.; Wu, J.; Zeng, D.; Liao, Y. A comparative study on UV light activated porous $\mathrm{TiO}_{2}$ and $\mathrm{ZnO}$ film sensors for gas sensing at room temperature. Ceram. Int. 2012, 38, 503-509. [CrossRef]

68. Yu, J.H.; Choi, G.M. Selective $\mathrm{CO}$ gas detection CuO-and $\mathrm{ZnO-doped} \mathrm{SnO}_{2}$ gas sensor. Sens. Actuators B 2001, 75, 56-61. [CrossRef]

69. Xiang, X.; Zhu, D.; Wang, D. Enhanced formaldehyde gas sensing properties of La-doped $\mathrm{SnO}_{2}$ nanoparticles prepared by ball-milling solid chemical reaction method. J. Mater. Sci. Mater. Electron. 2016, 27, 7425-7432. [CrossRef]

70. Hu, Y.; Tan, O.K.; Cao, W.; Zhu, W. A low temperature nanostructured $\mathrm{SrTiO}_{3}$ thick film oxygen gas sensor. Ceram. Int. 2004, 30, 1819-1822. [CrossRef]

71. Wagh, M.; Patil, L.; Seth, T.; Amalnerkar, D. Surface cupricated $\mathrm{SnO}_{2}-\mathrm{ZnO}$ thick films as a $\mathrm{H}_{2} \mathrm{~S}$ gas sensor. Mater. Chem. Phys. 2004, 84, 228-233. [CrossRef]

72. Chang, S.-P.; Chen, K.-J. Zinc oxide nanoparticle photodetector. J. Nanomater. 2012, 2012, 1-5. [CrossRef]

73. Gimenez, A.J.; Yáñez-Limón, J.M.; Seminario, J.M. ZnO-cellulose composite UV sensing. IEEE Sens.J. 2012, 13, 1301-1306. [CrossRef]

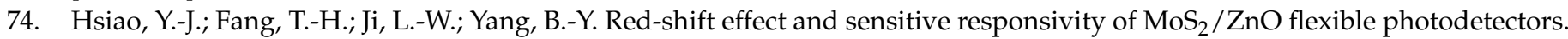
Nanoscale Res. Lett. 2015, 10, 1-5. [CrossRef]

75. Rasband, W.S.; ImageJ, U.S. National Institutes of Health, Bethesda, Maryland, USA, 1997-2016. Available online: https: / /imagej.nih.gov/ij/ (accessed on 16 September 2021).

76. Saikia, L.; Bhuyan, D.; Saikia, M.; Malakar, B.; Dutta, D.K.; Sengupta, P. Photocatalytic performance of ZnO nanomaterials for self sensitized degradation of malachite green dye under solar light. App. Catal. A: Gen 2015, 490, 42-49. [CrossRef]

77. Amutha, A.; Amirthapandian, S.; Sundaravel, B.; Panigrahi, B.K.; Saravanan, K.; Thangadurai, P. Low-temperature photoluminescence behaviour of Ag decorated ZnO Nanorods. J. Appl. Phys 2016, 120, 205104. [CrossRef]

78. Zhang, W.C.; Wu, X.L.; Chen, H.T.; Zhu, J.; Huang, G.S. Excitation wavelength dependence of the visible photoluminescence from amorphous ZnO Granular films. J. Appl. Phys 2008, 103, 093718. [CrossRef]

79. Damen, T.C.; Porto, S.P.S.; Tell, B. Raman Effect in Zinc Oxide. Phys. Rev. 1966, 142, 570-574. [CrossRef]

80. Cuscó, R.; Alarcón-Lladó, E.; Ibáñez, J.; Artús, L.; Jiménez, J.; Wang, B.; Callahan, M.J. Temperature dependence of Raman scattering in ZnO. Phys. Rev. B 2007, 75, 165202. [CrossRef]

81. Choi, Y.I.; Jung, H.J.; Shin, W.G.; Sohn, Y. Band-gap engineered ZnO and Ag/ZnO by ball milling method and their photocatalytic and Fenton-like photocatalytic activities. Appl. Surf. Sci. 2015, 356, 615-625. [CrossRef]

82. Šćepanović, M.; Grujić-Brojčin, M.; Vojisavljević, K.; Bernik, S.; Srećković, T. Raman study of structural disorder in ZnO nanopowders. J. Raman Spectrosc. 2010, 41, 914-921. [CrossRef]

83. Vojisavljevic, K.; Šcepanovic, M.; Sreckovic, T.; Grujic-Brojcin, M.; Brankovic, Z.; Brankovic, G. Structural characterization of mechanically milled ZnO: Influence of zirconia milling media. J. Phys. Condens. Matter 2008, 20, 475202. [CrossRef]

84. Singh, J.; Sharma, S.; Soni, S.; Sharma, S.; Singh, R.C. Influence of different milling media on structural, morphological and optical properties of the $\mathrm{ZnO}$ nanoparticles synthesized by ball milling process. Mater. Sci. Semicond. Process. 2019, 98, 29-38. [CrossRef]

85. Jung, H.J.; Sohn, Y.; Sung, H.G.; Hyun, H.S.; Shin, W.G. Physicochemical properties of ball milled boron particles: Dry vs wet ball milling process. Powder Technol. 2015, 269, 548-553. [CrossRef]

86. Ou, J.Z.; Ge, W.; Carey, B.; Daeneke, T.; Rotbart, A.; Shan, W.; Wang, Y.; Fu, Z.; Chrimes, A.F.; Wlodarski, W.; et al. PhysisorptionBased Charge Transfer in Two-Dimensional $\mathrm{SnS}_{2}$ for Selective and Reversible $\mathrm{NO}_{2}$ Gas Sensing. ACS Nano 2015, 9, 10313-10323. [CrossRef] [PubMed]

87. Li, S.; Wu, J.; Wang, Z.M.; Jiang, Y. Nanoscale Sensors; Lecture Notes in Nanoscale Science and Technology; Springer International Publishing: Berlin/Heidelberg, Germany, 2013; ISBN 9783319027722.

88. Kumar, R.; Al-Dossary, O.; Kumar, G.; Umar, A. Zinc oxide nanostructures for $\mathrm{NO}_{2}$ gas-sensor applications: A review. Nanomicro Lett. 2015, 7, 97-120. [CrossRef] [PubMed]

89. Ahn, M.-W.; Park, K.-S.; Heo, J.-H.; Park, J.-G.; Kim, D.-W.; Choi, K.J.; Lee, J.-H.; Hong, S.-H. Gas sensing properties of defect-controlled ZnO-nanowire gas sensor. Appl. Phys. Lett. 2008, 93, 263103. [CrossRef]

90. Yu, L.; Guo, F.; Liu, S.; Yang, B.; Jiang, Y.; Qi, L.; Fan, X. Both oxygen vacancies defects and porosity facilitated $\mathrm{NO}_{2}$ gas sensing response in 2D ZnO nanowalls at room temperature. J. Alloys Compd. 2016, 682, 352-356. [CrossRef]

91. Yuan, Z.; Li, R.; Meng, F.; Zhang, J.; Zuo, K.; Han, E. Approaches enhancing gas sensing properties: A review. Sensors 2019, 19, 1495. [CrossRef] 
92. Abe, S.; Choi, U.-S.; Shimanoe, K.; Yamazoe, N. Influences of ball-milling time on gas sensing properties of $\mathrm{Co}_{3} \mathrm{O}_{4}-\mathrm{SnO}_{2}$ composites. Sens. Actuators B 2005, 107, 516-522. [CrossRef]

93. Viswanathan, R.; Gupta, R.B. Formation of zinc oxide nanoparticles in supercritical water. J. Supercrit. Fluids 2003, 27, 187-193. [CrossRef]

94. Matsoukas, T.; Friedlander, S.K. Dynamics of aerosol agglomerate formation. J. Colloid Interface Sci. 1991, 146, 495-506. [CrossRef]

95. Medina, J.; Bolaños, H.; Mosquera-Sanchez, L.P.; Rodriguez-Paez, J. Controlled synthesis of ZnO nanoparticles and evaluation of their toxicity in Mus musculus mice. Int. Nano Lett. 2018, 8, 165-179. [CrossRef]

96. Wang, C.; Yin, L.; Zhang, L.; Xiang, D.; Gao, R. Metaloxide gas sensors: Sensitivity and influencing factors. Sensors 2010, 10, 2088-2106. [CrossRef]

97. Göpel, W.; Lampe, U. Influence of defects on the electronic structure of zinc oxide surfaces. Phys. Rev. B 1980, 22, 6447-6462. [CrossRef]

98. Aggelopoulos, C.A.; Dimitropoulos, M.; Govatsi, A.; Sygellou, L.; Tsakiroglou, C.D.; Yannopoulos, S.N. Influence of the surface-to-bulk defects ratio of $\mathrm{ZnO}$ and $\mathrm{TiO}_{2}$ on their UV-mediated photocatalytic activity. Appl. Catal. B 2017, 205, $292-301$. [CrossRef]

99. Tsukazaki, A.; Ohtomo, A.; Kawasaki, M. High-mobility electronic transport in ZnO thin films. Appl. Phys. Lett. 2006, 88, 152106. [CrossRef]

100. Wal, R.L.V.; Hunter, G.W.; Xu, J.C.; Kulis, M.J.; Berger, G.M.; Ticich, T.M. Metal oxide nanostructure and gas-sensing performance. Sens. Actuators B 2009, 138, 113-119. [CrossRef]

101. Hong, R.; Pan, T.; Qian, J.; Li, H. Synthesis and surface modification of ZnO nanoparticles. Chem. Eng. J. 2006, 119, 71-81. [CrossRef]

102. Ozcan, S.; Can, M.M.; Ceylan, A. Single step synthesis of nanocrystalline ZnO via wet milling. Mater. Lett. 2010, 64, 2447-2449. [CrossRef]

103. Faure, B.; Salazar-Alvarez, G.; Ahniyaz, A.; Villaluenga, I.; Berriozabal, G.; Miguel, Y.R.D.; Bergström, L. Dispersion and surface functionalization of oxide nanoparticles for transparent photocatalytic and UV protecting coatings and sunscreens. Sci. Technol. Adv. Mater. 2013, 14, 023001. [CrossRef] [PubMed]

104. Wang, X.; Yee, S.S.; Carey, W.P. Transition between neck-controlled grain-boundary-controlled sensitivity of metal-oxide gas sensors. Sens. Actuators B 1995, 25, 454-457. [CrossRef]

105. Jacobs, C.B.; Maksov, A.B.; Muckley, E.S.; Collins, L.; Mahjouri-Samani, M.; Ievlev, A.; Rouleau, C.M.; Moon, J.-W.; Graham, D.E.; Sumpter, B.G.; et al. UV activated ZnO films flexible substrate Room temperature $\mathrm{O}_{2} \mathrm{H}_{2} \mathrm{O}$ sensing. Sci. Rep. 2017, 7, 6053. [CrossRef] [PubMed]

106. Lee, J.-H.; Kim, J.-Y.; Mirzaei, A.; Kim, H.; Kim, S. Significant enhancement of hydrogen-sensing properties of ZnO nanofibers through NiO loading. Nanomaterials 2018, 8, 902. [CrossRef] [PubMed]

107. Takahashi, Y.; Kanamori, M.; Kondoh, A.; Minoura, H.; Ohya, Y. Photoconductivity of Ultrathin Zinc Oxide Films. Jpn. J. Appl. Phys 1994, 33, 6611-6615. [CrossRef]

108. Scolfaro, D.; Onofre, Y.; Teodoro, M.D.; Godoy, M. de Atmosphere-Dependent Photoconductivity of ZnO in the Urbach Tail. Int. J. Photoenergy 2018, 2018. [CrossRef]

109. Kulwicki, B.M. Humidity Sensors. J. Am. Ceram. Soc. 1991, 74, 697-708. [CrossRef]

110. Chen, Z.; Lu, C. Humidity sensors review of materials and mechanisms. Sens. Lett. 2005, 3, 274-295. [CrossRef]

111. Gupta, S.P.; Pawbake, A.S.; Sathe, B.R.; Late, D.J.; Walke, P.S. Superior humidity sensor and photodetector of mesoporous ZnO nanosheets at room temperature. Sens. Actuators B 2019, 293, 83-92. [CrossRef]

112. Jiao, M.; Van Duy, N.; Hoa, N.D.; Van Hieu, N.; Hjort, K.; Nguyen, H. Comparison $\mathrm{NO}_{2}$ gas-sensing properties of three different $\mathrm{ZnO}$ nanostructures synthesized by on-Chip low-temperature hydrothermal growth. J. Electron. Mater. 2018, 47, 785-793. [CrossRef]

113. Khatibani, A.B. Investigation of gas sensing property of Zinc oxide thinfilms deposited by Sol-Gel method: Effects of molarity and annealing temperature. Indian J. Phys. 2021, 95, 243-252. [CrossRef]

114. Hjiri, M.; Bahanan, F.; Aida, M.; El Mir, L.; Neri, G. High performance CO Gas Sensor Based on ZnO Nanoparticles. J. Inorg. Organomet. Polym. Mater. 2020, 30, 4063-4071. [CrossRef]

115. Moon, W.J.; Yu, J.H.; Choi, G.M. The $\mathrm{CO}$ and $\mathrm{H}_{2}$ gas selectivity of $\mathrm{CuO}$-doped $\mathrm{SnO}_{2}-\mathrm{ZnO}$ composite gas sensor. Sens. Actuators $B$ 2002, 87, 464-470. [CrossRef]

116. Huang, B.-R.; Lin, J.-C. A facile synthesis of ZnO nanotubes and their hydrogen sensing properties. Appl. Surf. Sci. 2013, 280, 945-949. [CrossRef]

117. Yoon, D.H.; Yu, J.H.; Choi, G.M. CO gas sensing properties of ZnO-CuO composite. Sens. Actuators B: Chem. 1998, 46, 15-23. [CrossRef]

118. Phan, D.-T.; Chung, G.-S. Effects of different morphologies of ZnO films on hydrogen sensing properties. J. Electroceramics 2014, 32, 353-360. [CrossRef]

119. Khan, R.; Ra, H.-W.; Kim, J.T.; Jang, W.S.; Sharma, D.; Im, Y.H. Nanojunction effects in multiple ZnO nanowire gas sensor. Sens. Actuators B 2010, 150, 389-393. [CrossRef] 
120. Mirzaei, A.; Leonardi, S.; Neri, G. Detection of hazardous volatile organic compounds (VOCs) by metal-oxide nanostructuresbased gas sensors A review. Ceram. Int. 2016, 42, 15119-15141. [CrossRef]

121. Dobrokhotov, V.; Oakes, L.; Sowell, D.; Larin, A.; Hall, J.; Kengne, A.; Bakharev, P.; Corti, G.; Cantrell, T.; Prakash, T.; et al. Toward the nanospring-based artificial olfactory system for trace-detection of flammable explosive vapors. Sens. Actuators B 2012, 168, 138-148. [CrossRef] 